\title{
Dynamic Analysis of Model Steel Structures Retrofitted with GFRP Composites under Microtremor Vibration
}

\author{
Sertaç Tuhta, Furkan Günday, Hakan Aydın \\ Department of Civil Engineering, Ondokuz Mayis University, \\ Faculty of Engineering Atakum, Samsun, Turkey
}

\begin{abstract}
There are many varieties of the structural and architectural structures strengthened with different FRP composites are gaining popularity, and there is a growing need to understand and compare the behavior of these structures before-after GFRP composite strengthening. In this study, model steel structure was tested on the bench-scale earthquake simulator (The Quanser Shake Table) using ambient vibration, to determine the dynamic response. After this, slabs of the model steel structure was strengthened with GFRP composite, and tested on the bench-scale earthquake simulator (The Quanser Shake Table) using ambient vibration, to determine the dynamic behavior. Finally, dynamic responses of model steel structure before and after GFRP composite strengthening, such as displacements and maximum-minimum acceleration, were compared. At the end of the study, it is seen that displacements had decreased along the height of the model steel structure. Also, it is seen from the earthquake analyses that GFRP strengthening is very effective on the dynamic responses of the model steel structure.
\end{abstract}

Keywords: Dynamic Analysis; GFRP; Microtremor Vibration; Shake Table

\section{INTRODUCTION}

Most of structures located in regions prone to earthquake hazards suffer from various types of destruction caused by seismic loads. Under such earthquake occurring, the parts (especially the columns) of building structures suffer damage. Looking on the other side, especially considering the performance of such buildings under seismic occurrence, there is a great need to strengthen the columns even without changing their building masses; this clearly shows that there is a need to investigate the connection between technical repairing or strengthening procedures and the column capacity. In this understanding, more researches are being conducted to get required performance of structures under seismic loading, by means of looking at different point of view and directions.

In the literature, there are so many studies relation with the behavior of structures or structural frame elements before and after FRP composite retrofitting. Carbon fiber composites and high performance fiber reinforced composites (AFRP, BFRP, HMCF, etc.) utilized for the last 30 years by the aircraft, space and many industries, may be employed to strengthen existing structures for civil engineering purposes. Recently, application of fiber reinforced plastic composite system by gluing them to external part of the reinforced concrete structures is gradually becoming popular for the aim of repairing and strengthening (Yang et al. 2017), Keykha (2017), (Smyrou et al. 2015), Elwan and Omar (2014). Fibers to be used, as they have required characteristics include: glass, aramid and carbon. The production of these fibers is done in two ways: either as plates (covered by thin fibers) or as tissues (knitted in one and two directions). The behavior of the system that is covered with external FRP composite is related to the type of the element covered. Generally FRPs have been separated into three categories: bending strengthening, shear strengthening and envelope scripts. In order to strengthen reinforced concrete structures, the prevention of severe bending and shearing is realized by covering beams by FRP composite. Increasing the resistance and ductility of the system under lateral seismic loads the main goal of this covering. Li and Sung in (2003) they had presented lot of analytical and experimental tests on benchmark and on reinforced concrete damaged circular bridge column. In the benchmark column is a $40 \%$ scale reinforced concrete circular bridge column damaged because of shear failure during a cyclic- loading test. Then the column repaired by epoxy and non- shrinkage mortar and rehabilitated by (GFRP) carbon fiber reinforced plastic after the cyclic-loading test. Experimental result could be predicted accurately by the analytical lateral forcedisplacement relationship of the bridge columns, especially in the nonlinear regions. In their study, for circular reinforced concrete bridge column, the result has been reached so that for a true repair; a change of the shearfailure mode of bridge column to the bending-failure refraction occurs, in other words this increases the seismic performance the analytical and experimental by (Montoya et al. 2004) are fitted with the numerical results of nonlinear finite element evaluation for the behavior of steel and FRP contained concrete columns which formulated and implemented. The performance of reinforced concrete column which was covered with carbon FRP was determined under uniaxial compression load Cole (2001). When Strengthened with CF-130 carbon fiber laminates, the experimental result for five circular columns and three rectangular columns were tested in pure compression shows that $\mathbf{\pm 4 5}$ degrees GFRP laminate can effectively be used to provide columns ductility performance. When the main goal is to boost the load capacity, a unidirectional FRP laminate might be more effective according to Paretti and Nanni (2002). According to Parvin and Wang study (2002), they talk over the effect of strain gradient and FRP thickness on square concrete columns reinforced with FRP wraps. The results for nine square concrete columns were tested under eccentric load and two different levels of eccentricity. It was shown that the chosen eccentricity values were small enough to produce any longitudinal tension in the wrap. The aim of this study is 
to evaluate the performance of reinforced concrete column, which has rectangular cross-section, under axial static compression load by using analytical, numerical and experimental evaluations and also to increase the source of statistics with a comparison target on this field. It has been shown that beams of existing structures suffer too much during seismic loading. Reinforced concrete rectangular cross-section column was used to evaluate their performance under axial static compression load by using analytical, numerical and experimental evaluations and also to increase the source of statistics with a comparison target on this field. It has been shown that beams of existing structures suffer too much during seismic loading.

analytical and experimental results by testing "T" cross section reinforced concrete beam, the beams strengthen with carbon fiber reinforced plastic composite (GFRP), the results show that tension increased at the negative moment region approximately $40 \%$ according to (Namboorimadathil et al. 2002) study. The distance from support to GFRP origin and effect of cross-section beam and its behavior have been studied in (Ahmed et al. 2001) study, when it was strengthened with GFRP composite at the tensile region of reinforced concrete beam. Computation formula has been composed related to experimental results, to guess the design load that is equal to the limit position of beam. In this examination original shear stress and slight effect have been taken into consideration. The performance of partial bridge strengthened by GFRP composite has been tested in (Ramos et al. 2004) study. On partial scaled and full-scaled specimen, partial beams experiments were conducted. Bond scaled experiment has been shown as alternative for characterizing repair and strengthening the partial structures with GFRP composite. For pre-stressed three reinforced concrete girder bridge that suffered damage which repair-strengthening with GFRP composite. Experimental results before and after repairing was presented by (Klaiber et al. 2003) study, the results shown that using of GFRP is productive. The girder bending displacements have been decreased more than $20 \%$ when GFRP was used. When Strengthened with CF-130 carbon fiber laminates, fifteen rectangular beams were tested in pure compression. The experimental result shows that GFRP laminate can effectively be used to provide beams ductility performance. The effect of FRP wrapping number to the maximum axial capacity has been evaluated Kasimzade and Tuhta (2012).

The Quanser Shake Table is a bench-scale earthquake simulator ideal for teaching structural dynamics, control topics related to earthquake, aerospace and mechanical engineering and it is widely used in applications. In this study investigated is the possibility of using the recorded micro tremor data on ground level as ambient vibration input excitation data for investigation, and the application of Operational Modal Analysis (OMA) on the bench-scale earthquake simulator (The Quanser Shake Table) for model steel structure.

For this purpose, experimental modal analysis of a model steel structure for dynamic characteristics was evaluated. Then, retrofitted model steel structure for dynamic characteristics was also evaluated. Ambient excitation was provided by shake table from the recorded micro tremor ambient vibration data on ground level. The Enhanced
Frequency Domain Decomposition is used for the outputonly modal identification. Model steel structure was tested on the bench-scale earthquake simulator (The Quanser Shake Table) using ambient vibration, to determine the dynamic behavior. After this, slabs of the model steel structure was strengthened with FRP composite, and tested on the bench-scale earthquake simulator (The Quanser Shake Table) using ambient vibration, to determine the dynamic behavior.

\section{Description of model steel structure}

The Quanser shake table II is a uniaxial bench-scale shake table. This unit can be controlled by appropriate software illustrated in Figs. 1a, b, c. It is effective for various types of experiments in civil engineering structures and models. The specifications for the Shake table are shown below Quanser (2008):

TABLE 1 SHAKE TABLE SPECIFICATIONS

\begin{tabular}{|l|l|}
\hline Dimensions (H x L x W) & $(61 \times 46 \times 13) \mathrm{cm}$ \\
\hline Total mass & $27.2 \mathrm{~kg}$ \\
\hline Payload area (L x W) & $(46 \times 46) \mathrm{cm}$ \\
\hline Maximum payload at $2.5 \mathrm{~g}$ & $7.5 \mathrm{~kg}$ \\
\hline Maximum travel & $\pm 7.6 \mathrm{~cm}$ \\
\hline Operational bandwidth & $10 \mathrm{~Hz}$ \\
\hline Maximum velocity & $66.5 \mathrm{~cm} / \mathrm{s}$ \\
\hline Maximum acceleration & $2.5 \mathrm{~g}$ \\
\hline Lead screw pitch & $1.27 \mathrm{~cm} / \mathrm{rev}$ \\
\hline Servomotor power & $400 \mathrm{~W}$ \\
\hline $\begin{array}{l}\text { Amplifier maximum continuous } \\
\text { current }\end{array}$ & $12.5 \mathrm{~A}$ \\
\hline Motor maximum torque & $7.82 \mathrm{N.m}$ \\
\hline Lead screw encoder resolution & $8192 \mathrm{counts} / \mathrm{rev}$ \\
\hline Effective stage position resolution & $1.55 \mu \mathrm{m} / \mathrm{count}$ \\
\hline Accelerometer range & $\pm 49 \mathrm{~m} / \mathrm{s}^{2}$ \\
\hline Accelerometer sensitivity & $1.0 \mathrm{~g} / \mathrm{V}$ \\
\hline
\end{tabular}

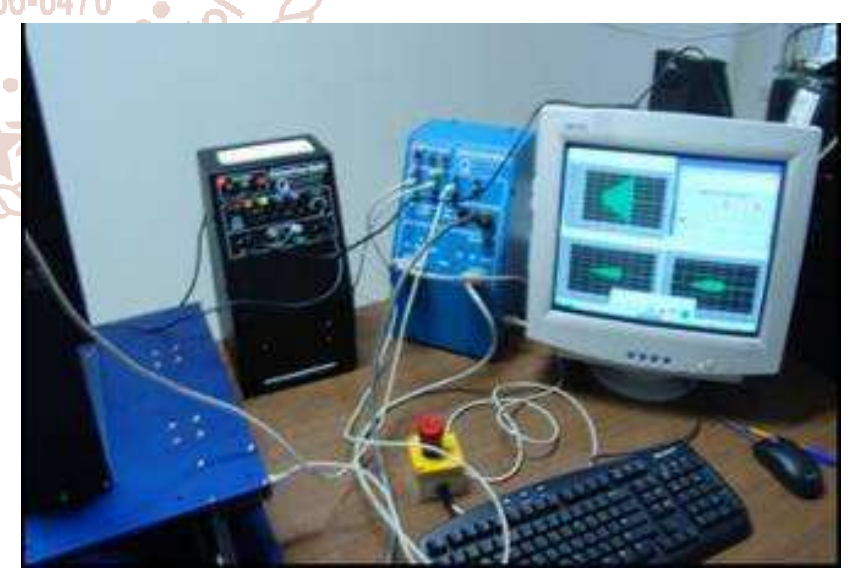

(a)

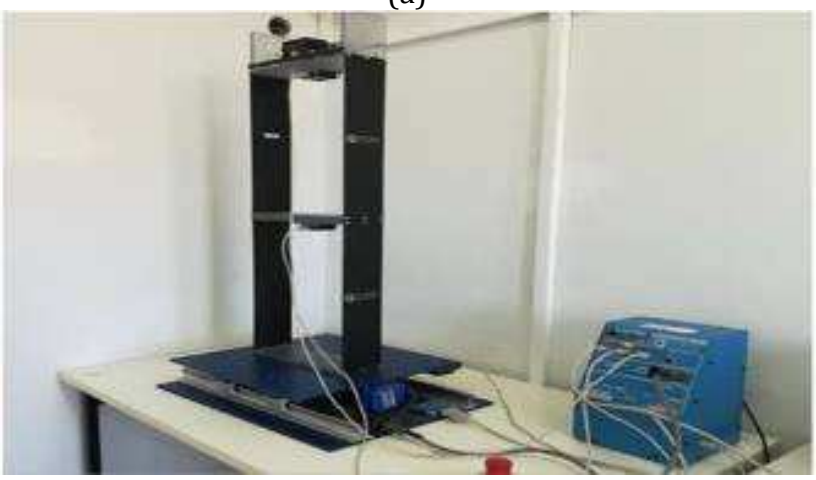

(b) 


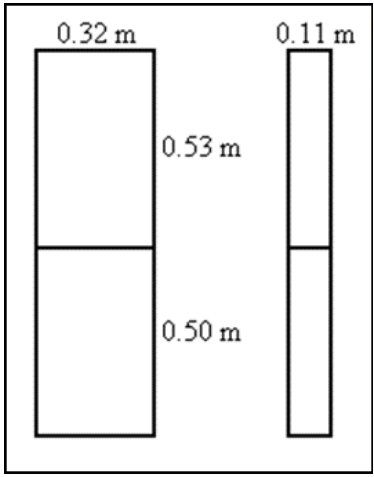

(c)

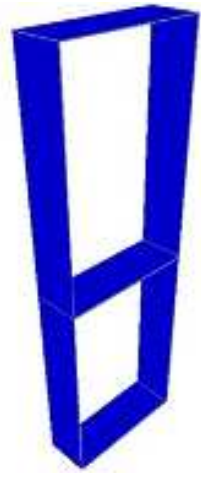

Figure 1a, b, c Illustration of model steel structure and shake table

In modeling of beams and columns the modulus of elasticity $E=2.000 \mathrm{E} 11 \mathrm{~N} / \mathrm{m}^{2}$, Poisson ratio $\mu=0.3$, mass per unit volume $\rho=78500 \mathrm{~N} / \mathrm{m}^{3}$. Model steel structure is $1.03 \mathrm{~m}$ height. Thickness of elements is $0.001588 \mathrm{~m}$. The structure dimensions are shown in Figure 1.

\section{Shake table test of model steel structure}

Real time history of model steel structure before and after FRP composite strengthening were performed by using acceleration values of ambient vibration. Record length is 100 minutes.

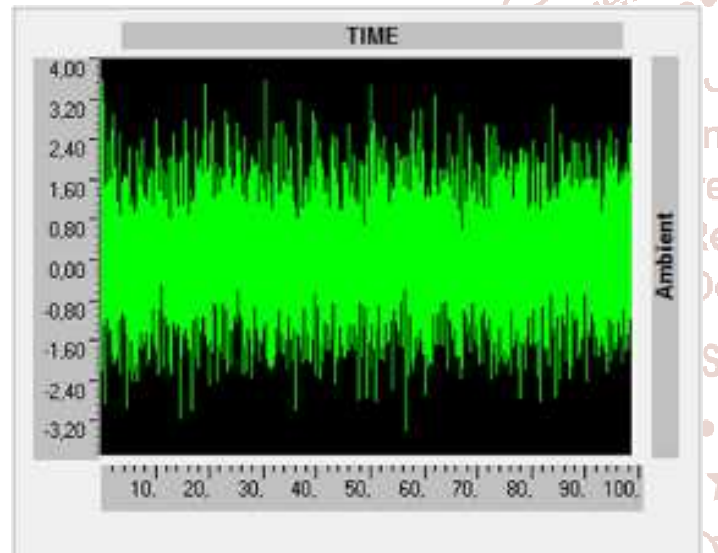

Figure 2 Ambient excitation data from the recorded micro tremor data on ground level used in the shake table

The excitation is provided by using ambient vibration on shake table. Two accelerometers A and B (with both $\mathrm{x}$ and $\mathrm{y}$ directional measures) are used to measure vibrations, one of them is allocated as first floor, and other second floor (shown by the red in Figure 3).

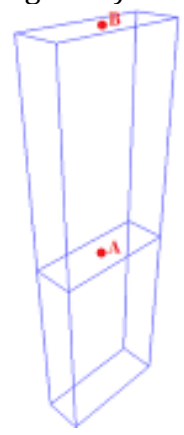

Figure 3 Accelerometers location of experimental model in the $3 D$ view
The absolute displacements and accelerations model steel structure at the time of response before and after FRP composite strengthening are given in table 2-3 and Figure 46.

TABLE 2 DISPLACEMENTS AND ACCELERATIONS OF EXISTING MODEL STEEL STRUCTURE

\begin{tabular}{|c|c|c|}
\hline Joint & Acceleration & Displacement \\
\hline A & 0.09360 & 0.0003490 \\
\hline B & 0.12510 & 0.0006343 \\
\hline
\end{tabular}

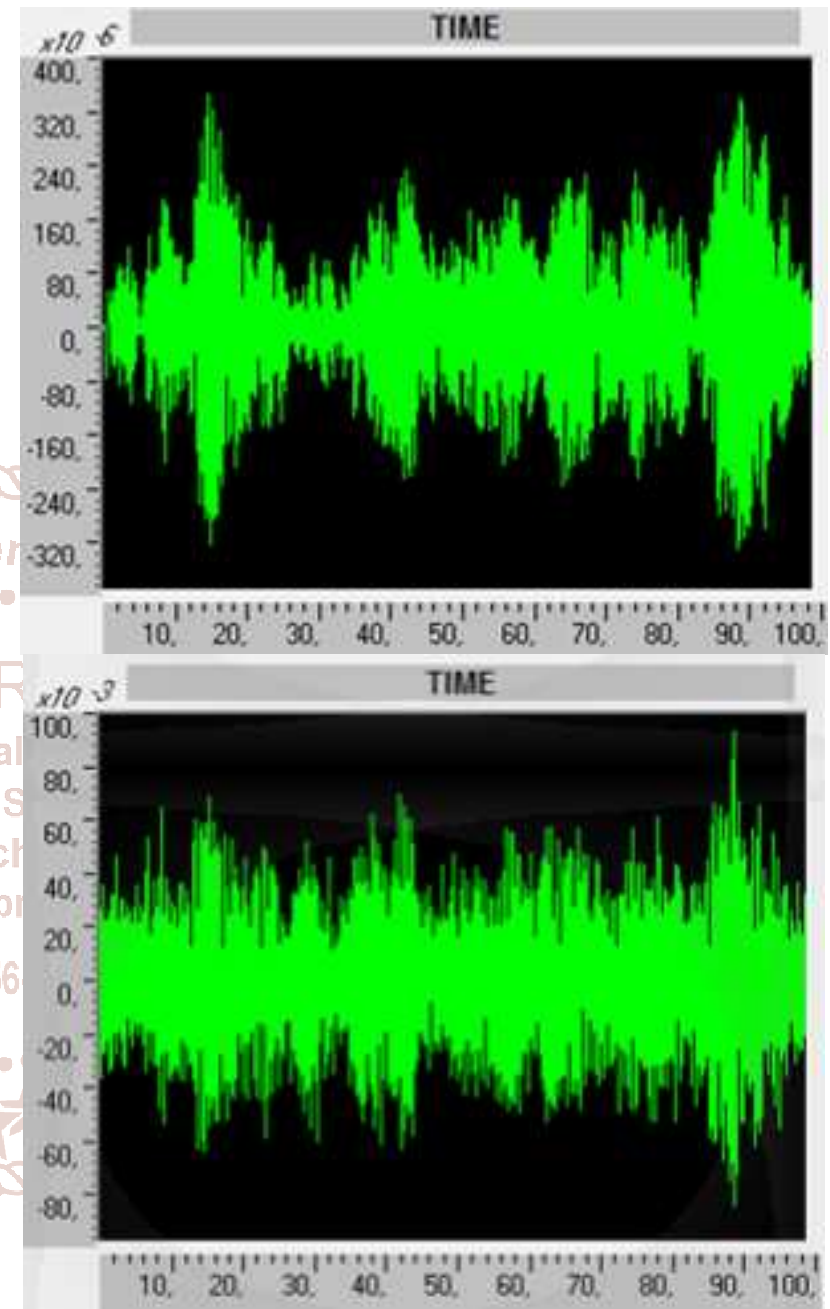

Figure 4a Node (A) Displacement and acceleration graphics

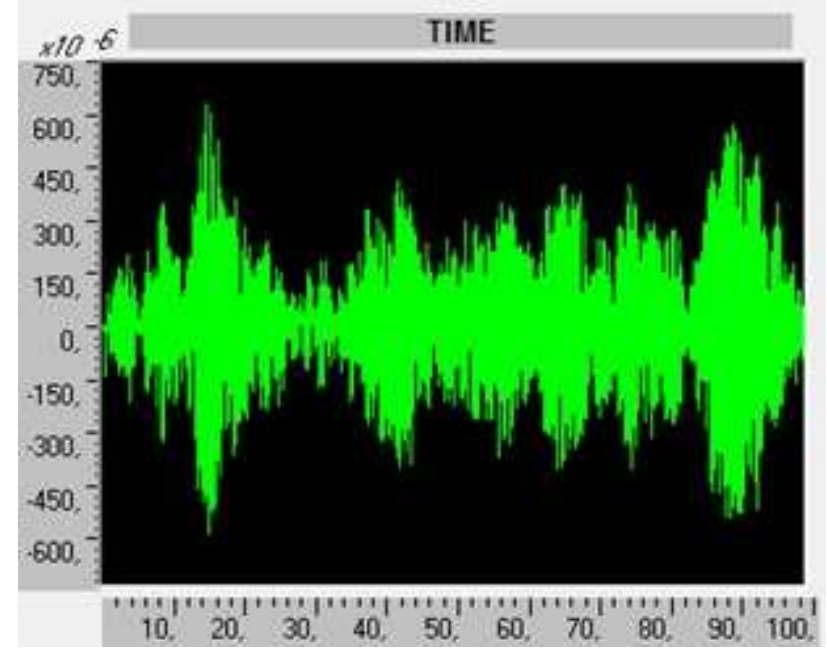




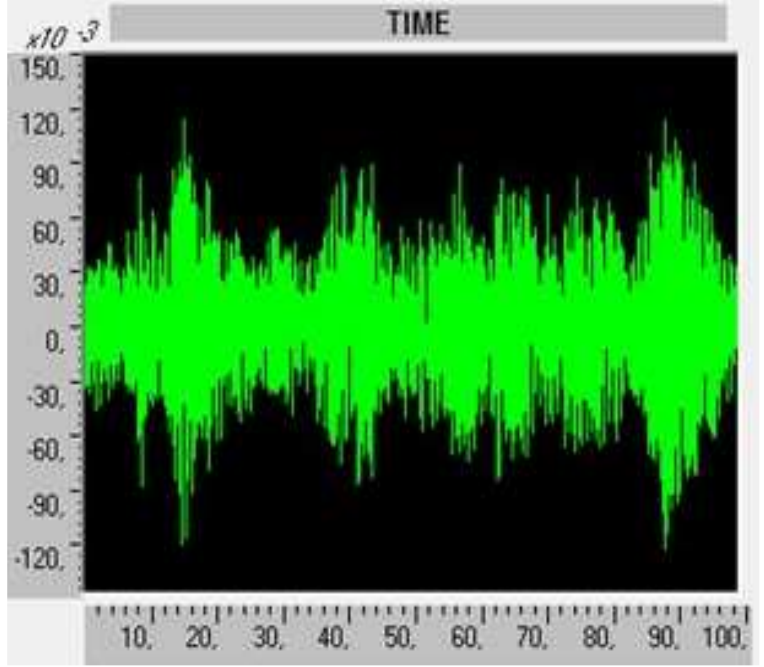

Figure 4b Node (B) Displacement and acceleration graphics

Shake table test of retrofitted model steel structure In the case of retrofitted beams, the following are studies made on it to check and examine the efficiency of using unidirectional GFRP composite: beams of the model steel structure are retrofitted with one layer GFRP composite. The Unidirectional GFRP composite and its components YKS Fiber is product of YKS Corporation (Figure 5). The properties of the dry carbon fiber composite are: $\mathrm{E}=4 \mathrm{E} 10$ $\mathrm{N} / \mathrm{m} 2$, Poisson ratio $\mu=0.25$, mass per unit volume $\rho=18639$ $\mathrm{N} / \mathrm{m} 3$, thickness $=0.000152 \mathrm{~m}$.

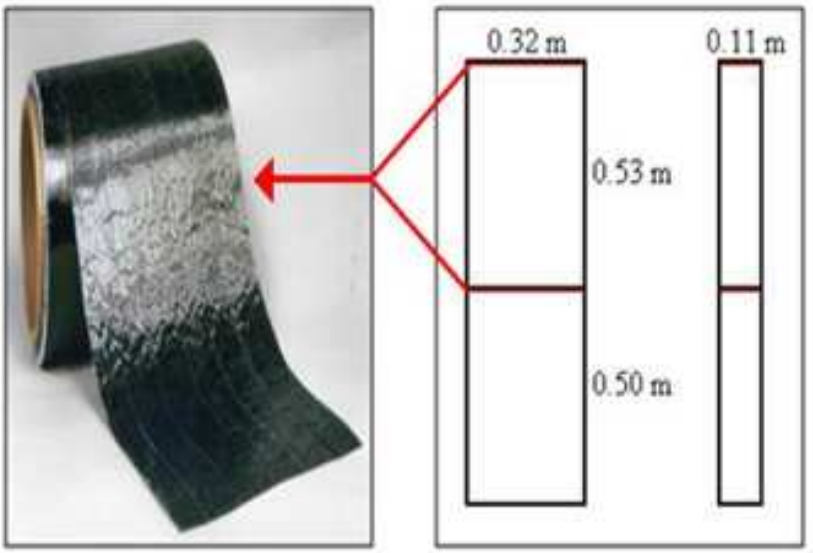

Figure 5 GFRP composite and using details

The steps to pass through during retrofitting are shown below in details: a thin layer two sided tape is applied (Figure 5) to the beams, approximately 1 hour of curing in order to prepare a surface for application of GFRP composite. Next step, bottomsurface of beams is covered with GFRP composites. After these setups, ambient vibration tests are followed by curing to obtain absolute displacements and accelerations similar to previously used properties in order to obtain comparative measurements (Figure 5 and table 3).

TABLE 3 DISPLACEMENTS AND ACCELERATIONS OF RETROFITTED MODEL STEEL STRUCTURE

\begin{tabular}{|c|c|c|}
\hline Joint & $\begin{array}{c}\text { Acceleration } \\
\left(\mathrm{m} / \mathrm{s}^{2}\right)\end{array}$ & $\begin{array}{c}\text { Displacement } \\
(\mathrm{m})\end{array}$ \\
\hline A & 0.10670 & 0.0001592 \\
\hline B & 0.12890 & 0.0003077 \\
\hline
\end{tabular}

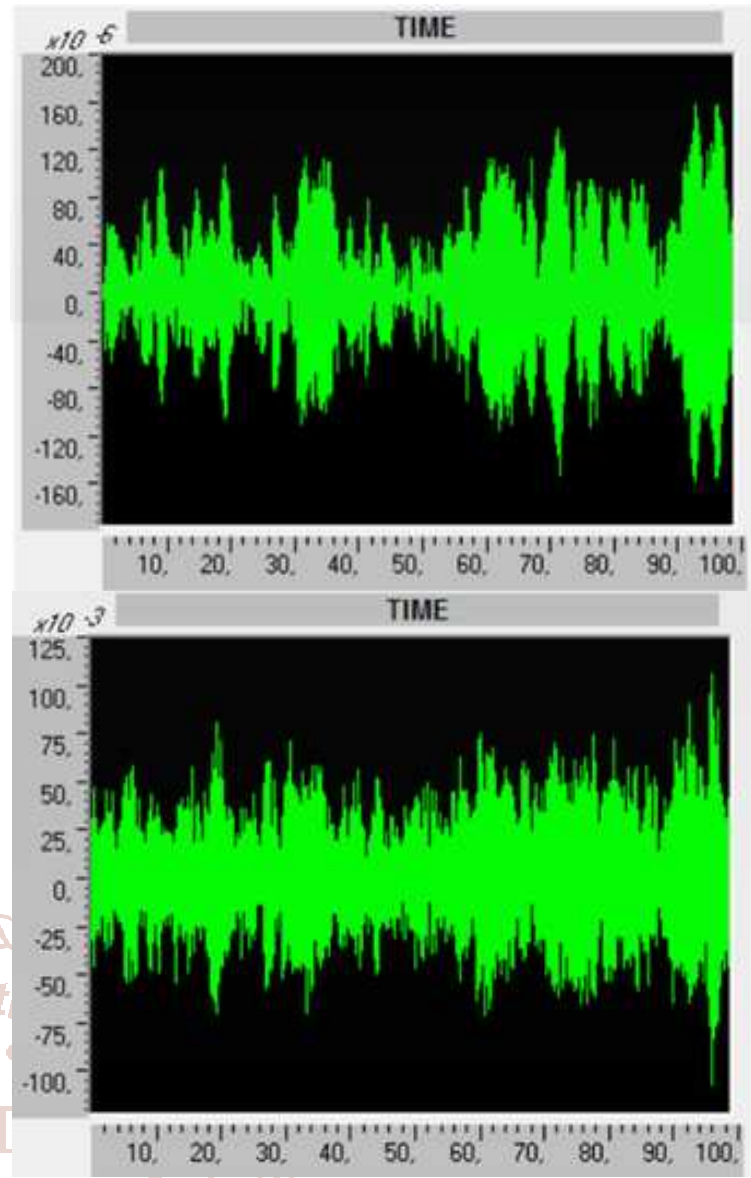

Figure 6a Node (A) Displacement and acceleration graphics

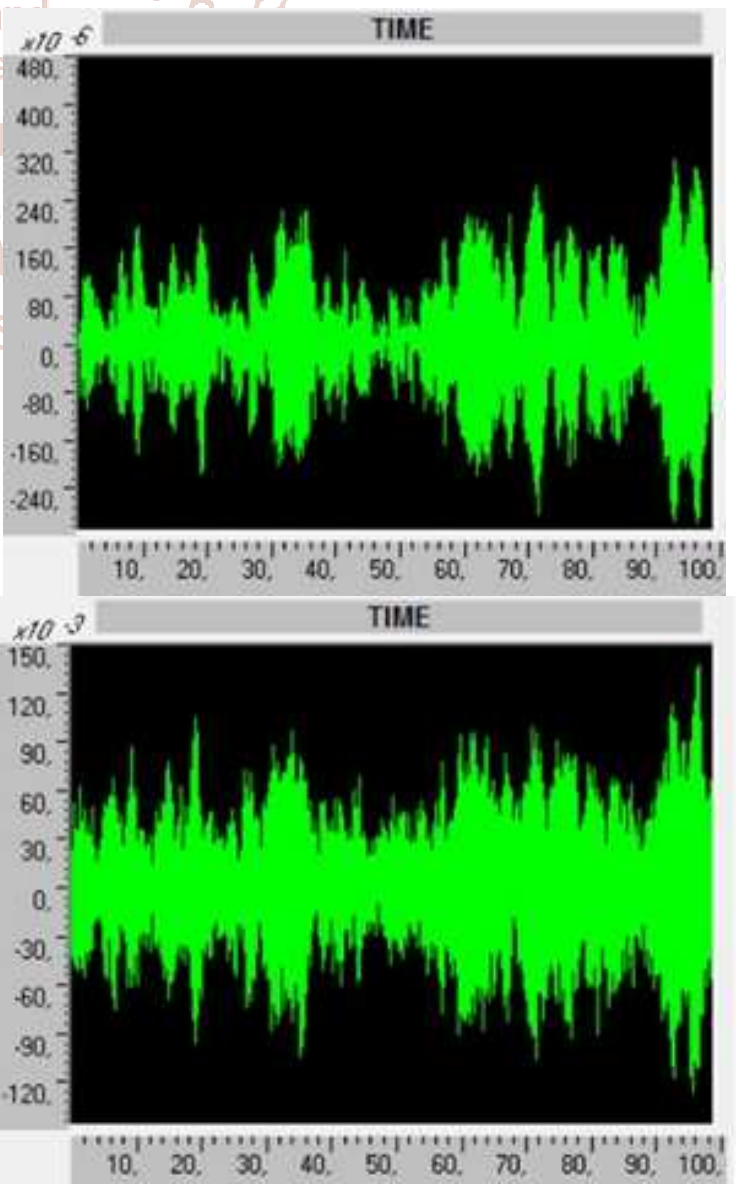

Figure 6b Node (B) Displacement and acceleration graphics 
It was clearly seen from Figure 5 that application of FRP to the model steel structure reduces the absolute displacement values along the height of the structure. In another words, the maximum absolute displacement value, $0.0006343 \mathrm{~m}$, before FRP application, decreased to $0.0003077 \mathrm{~m}$ after FRP application. The decrease in maximum absolute displacements was approximately $51,49 \%$ without so many additional mass to the structure. It is clearly seen from Figures. 4 and 5 that FRP composite is very effective.

It is clear that using GFRP composites seems to be very effective for strengthening steel members along with increasing stiffness; this research aims to determine how GFRP composite implementation affects structural response of model steel structure by changing of dynamic characteristics.

\section{Conclusions}

In this research, the conducted were both experimental analysis of existing model steel structure and GFRP composite retrofitted model steel structure. Comparing the result of study, the followings are noticed:

From the shake table test, displacements range between 0.0001592 and $0.0006343 \mathrm{~m}$.

The displacement difference lies in the interval of 51,49\%$54,38 \%$ for Existing and retrofitted case and it provides the increase of frame structure stiffness about 52,94\%;

The investigated results ensure and confirm the possibility of using the recorded micro tremor data on ground level as ambient vibration input excitation data for investigation and application of dynamic response on the bench-scale earthquake simulator (The Quanser Shake Table) for retrofitted structures and shed light on the development of related research.

The conclusion of the experiment strongly suggests that the retrofitting should be very efficient to increase stiffness and decrease displacement.

In this study, it is shown that shake table test may be used to evaluate the displacement and acceleration of the retrofitted structures.

\section{References}

[1] Ahmed, O., Van Gemert, D. and Vandewalle, L. (2001), "Improved model for plate-end shear of GFRP strengthened RC beams", Cement and Concrete Composites, 23(1), 3-19.

[2] Cole, C.B. (2001), "Performance of FRP-jacketed reinforced concrete columns subjected to uniaxial compression", MSc Dissertation, University of Missouri, Rolla, USA.

[3] Elwan, S. K. and Omar, M. A. (2014), "Experimental behavior of eccentrically loaded RC slender columns strengthened using GFRP wrapping", Steel and Composite Structures, 17(3), 271-285.

[4] Kasimzade, A.A. and Tuhta S. (2012), "Analytical, numerical and experimental examination of reinforced composites beams covered with carbon fiber reinforced plastic". Journal of Theoretical and Applied Mechanics, 42(1), 55-70.

[5] Keykha, A. H. (2017), "Numerical investigation on the behavior of SHS steel frames strengthened using GFRP", Steel and Composite Structures, 24(5), 561-568.

[6] Klaiber, F. W., Wipf, T. J. and Kempers, B. J. (2003), "Repair of damaged prestressed concrete bridges using GFRP", Mid-Continental Transportation Research Symposium, Ames, Iowa, USA, August.

[7] Li, Y. F. and Sung, Y. Y. (2003), "Seismic repair and rehabilitation of a shear-failure damaged circular bridge column using carbon fiber reinforced plastic jacketing", Canadian Journal of Civil Engineering, 30(5), 819-829.

[8] Montoya, E., Vecchio, F. J. and Sheikh, S. A. (2004), "Numerical evaluation of the behaviour of steel-and FRP- confined concrete columns using compression field modeling", Engineering Structures, 26(11), 15351545.

[9] Namboorimadathil, S. M., Tumialan, J. G. and Nanni, A. (2002), "Behavior of RC T beams strengthened in the negative moment region with GFRP laminates", Third International Conference on Composites in Infrastructure (ICCI'02), Francisco, California, USA, June.

[10] Parretti, R. and Nanni, A. (2002), "Axial testing of concrete columns confined with carbon FRP: effect of fiber orientation", Third International Conference on Composites in Infrastructure (ICCI'02), Francisco, California, USA, June.

[11] Parvin, A. and Wang, W. (2002), "Tests on concrete square columns confined by composite wraps", Third International Conference on Composites in Infrastructure (ICCI'02), Francisco, California, USA, June.

[12] Quanser (2008) Position control and earthquake analysis. Quanser Shake Table II User Manual, Nr 632, Rev 3.50, Quanser Inc, Markham, Canada.

[13] Ramos, G., Casas, J. R. and Alarcón, A. (2004), “Repair and strengthening of segmental bridges using carbon fibers", Engineering Structures, 26(5), 609-618.

[14] Smyrou, E., Karantzikis, M. and BAL, İ. E. (2015), "FRP versus traditional strengthening on a typical mid-rise Turkish RC building", Earthquakes and Structures, 9(5), 1069-1089.

[15] Yang, Y., Xue, Y., Yu, Y., Liu, R. and Ke, S. (2017), "Study of the design and mechanical performance of a GFRPconcrete composite deck", Steel and Composite Structures, 24(6), 679-688 